\title{
Effects of L-arginine on lower limb vasodilator reserve and exercise capacity in patients with chronic heart failure
}

\author{
Y Kanaya, M Nakamura, N Kobayashi, K Hiramori
}

\begin{abstract}
Objective-To determine whether the reactive hyperaemic response of the lower limb increases with improved exercise capacity after acute supplementation with L-arginine, the precursor of nitric oxide, in patients with chronic heart failure.

Methods-19 patients with chronic heart failure were enrolled in the study. Rest calf blood flow and femoral occlusion induced calf blood flow changes were measured by venous occlusion plethysmography before and after intravenous infusion of $10 \%$ L-arginine solution $(5 \mathrm{ml} / \mathrm{kg}$ for $30 \mathrm{~min}$ utes) or placebo. Postexercise calf blood flow was also measured after the experimental infusion. During both postinfusion periods, several exercise capacity indices were determined by a symptom limited cardiopulmonary exercise test using a bicycle ergometer.

Results-Baseline calf blood flow, systemic blood pressure, and heart rate showed no significant changes in either of the two experimental conditions. However, the occlusion induced blood flow response was significantly enhanced by L-arginine infusion (mean (SEM) peak flow, $19.6(1.5) v 28.9(3.1) \mathrm{ml} / \mathrm{min} / \mathrm{dl}$ calf tissue; $\mathbf{p}<0.01$ ), but not by placebo (peak flow, $19.1(1.4) v 20.9(1.8) \mathrm{ml} / \mathrm{min} / \mathrm{dl}$ calf tissue; NS). Calf blood flow response after exercise was also higher after L-arginine infusion than after placebo (peak flow, 4.8 (0.4) $v 6.0(0.8) \mathrm{ml} / \mathrm{min} / \mathrm{dl}$ calf tissue; p < 0.05). L-arginine infusion had no significant effect compared with placebo on exercise capacity indices such as peak oxygen uptake (17.1 (1.0) v 15.8 (1.1) $\mathrm{ml} / \mathrm{min} / \mathrm{kg}$; NS), anaerobic threshold (10.5 (0.6) $v 10.4(0.7) \mathrm{ml} / \mathrm{min} / \mathrm{kg} ; \mathrm{NS})$, and exercise time (296 (23) $v 283(22) \mathrm{s}$; NS).

Conclusions-Acute supplementation with the nitric oxide precursor $L$-arginine increased lower limb reactive hyperaemia but did not lead to any significant improvement in exercise capacity in patients with chronic heart failure.

(Heart 1999;81:512-517)
\end{abstract}

Keywords: congestive heart failure; nitric oxide; endothelium; arginine; exercise

Reduction of peripheral blood flow at rest and during exercise is a critical pathophysiological characteristic of patients with chronic heart failure. Several reports have suggested that inadequate blood flow to working skeletal muscle contributes to exercise intolerance ${ }^{1-3}$ It has recently been reported that the endothelium dependent vasodilator response in peripheral vessels is attenuated in patients with chronic heart failure, implying that this may be a partial cause of reduced peripheral blood flow. ${ }^{4-6}$ Nitric oxide (NO), a major component of endothelium derived relaxing factor, is a mediator of flow dependent vasodilatation. ${ }^{7}$ It follows that impaired $\mathrm{NO}$ production may reduce flow dependent vasodilatation and exercise capacity in patients with chronic heart failure.

Reactive hyperaemic blood flow after limb ischaemia is an indicator of maximum vasodilator reserve capacity, and lower limb reactive hyperaemia has been shown to be attenuated and to be directly correlated with exercise capacity in patients with chronic heart failure. ${ }^{8-10}$ It has also been suggested that reactive hyperaemia may be partly regulated by endothelium derived $\mathrm{NO}$ in the limb vasculature. ${ }^{11}{ }^{12}$ Endothelial cells produce NO from the amino acid L-arginine through NO synthase. ${ }^{1314}$ After infusion of $\mathrm{N}^{\mathrm{G}}$ monomethyl-L-arginine (L-NMMA), a specific inhibitor of $\mathrm{NO}$ synthase, forearm reactive hyperaemia has been reported to be reduced in normal subjects. ${ }^{11}{ }^{12}$ L-arginine infusion enhances femoral arterial blood flow in patients with critical limb ischaemia, ${ }^{15}$ and increases forearm vasodilator response during acetylcholine infusion and reactive hyperaemia in patients with chronic heart failure. ${ }^{16}$ However, it is not known whether lower limb reactive hyperaemia increases with improvement in exercise capacity after supplementation with L-arginine in patients with chronic heart failure.

We have examined reactive hyperaemic response in the lower limb in patients with chronic heart failure to determine whether an increase occurred with improvement in exercise capacity after acute supplementation with L-arginine.

\section{Methods}

The study protocol was approved by our medical university hospital ethics committee, and informed consent was obtained from all patients.

SUBJECTS

Nineteen patients with chronic heart failure without valvar stenotic lesions were enrolled in the study. Their age ranged from 29 to 74 


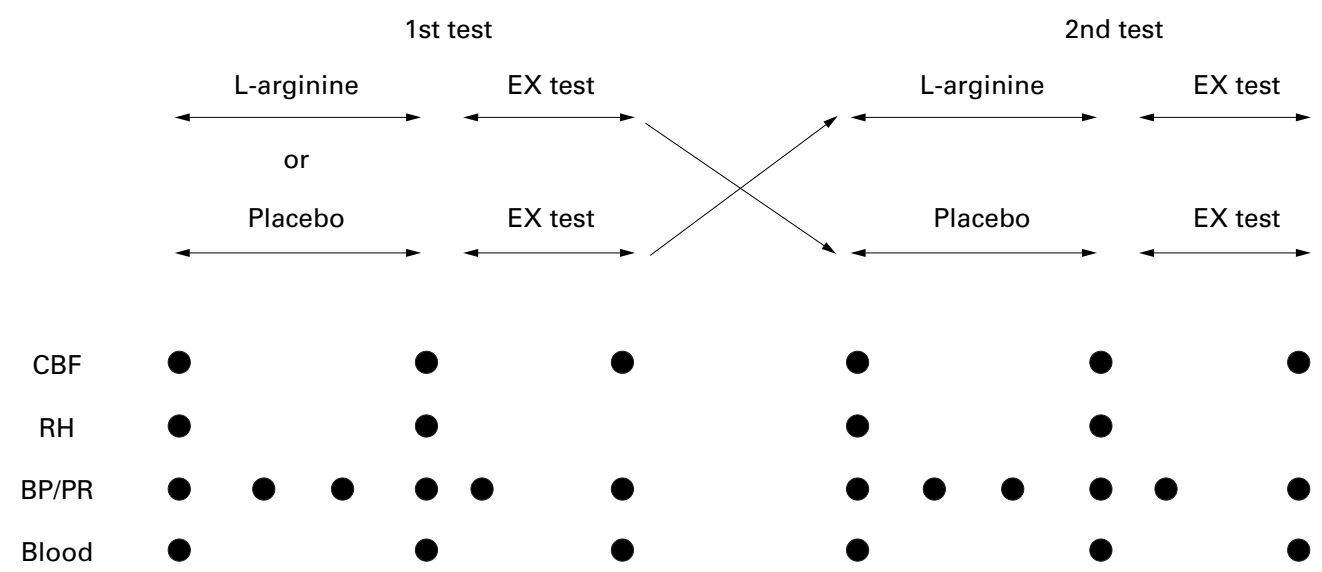

Figure 1 Study protocol. Blood, blood sampling; BP/HR, blood pressure and heart rate; CBF, calf blood flow; EX test, symptom limited cardiopulmonary exercise test; $R H$, reactive hyperaemia.

years, mean (SEM) 57 (3) years. There were 13 males and six females.

The underlying heart disease was mainly primary cardiomyopathy or valvar heart disease. Complications included atrial fibrillation (6), diabetes mellitus (4), and hypertension (3). At the time of the study, two patients were in New York Heart Association functional class I, 12 were in class II, and five were in class III. The left ventricular ejection fraction averaged 41 (3) \%. Eleven of the 19 patients were being treated with angiotensin converting enzyme inhibitors, five were using glyceryl trinitrate, 14 were on digitalis, and 11 were on diuretics. Administration of these drugs was discontinued at least 12 hours before the start of the study.

Controls consisted of eight healthy age and sex matched volunteers (mean age 58 (3) years), none of whom had hyperlipidaemia (serum cholesterol $4.35(0.23) \mathrm{mmol} / \mathrm{l})$. Mean serum cholesterol in the patient group was 4.30 (0.18) $\mathrm{mmol} / \mathrm{l}$. Treatment with lipid lowering drugs in the patient group accounted for their normal serum cholesterol values.

There were five current smokers in the patient group and three in the control group (NS).

BLOOD FLOW MEASUREMENT

This study was conducted with a randomised single blind crossover design (fig 1). Calf blood flow ( $\mathrm{ml} / \mathrm{min} / 100 \mathrm{ml}$ calf tissue) was measured by venous occlusion strain gauge plethysmography. The strain gauge was positioned on the left calf at the point of maximum circumference. The lower limb was angulated to approximately $20^{\circ}$ using a specially made foam block. Foot circulation was excluded by inflating an ankle cuff to more than $200 \mathrm{~mm} \mathrm{Hg}$. A thigh congesting cuff was expanded to $60 \mathrm{~mm}$ $\mathrm{Hg}$ by the inflator for 7.5 seconds in each 15 second cycle using a time switch.

After the subjects had remained supine for 20 minutes, resting calf blood flow was measured for two minutes. The mean value of the last four consecutive flow measurements was presented as baseline calf blood flow. For measurement of occlusion induced reactive hyperaemic blood flow, the thigh cuff was inflated to more than $170 \mathrm{~mm} \mathrm{Hg}$ (suprasystolic pressure) by the cuff inflator for five minutes. Postocclusion calf blood flow was measured serially every 15 seconds for three minutes after abrupt release of the arterial occlusion. All consecutive flow curves were analysed and a flow versus time curve constructed. L-arginine solution $(10 \%)$ or dextrose solution (5\%), as a placebo, was infused at a rate of $5 \mathrm{ml} / \mathrm{kg}$ for 30 minutes through a $21 \mathrm{G}$ butterfly needle into a right forearm cutaneous vein. The order of infusion was randomised and the interval between infusions was usually between one and two weeks. Resting calf blood flow and femoral artery occlusion induced reactive hyperaemia were measured before and after both infusions.

Systemic blood pressure and pulse rate of the left arm were measured by an automatic blood pressure monitoring system throughout the

Table 1 Effects of L-arginine and placebo infusion on resting (supine) and exercise induced (seated) systemic blood pressure and heart rate in patients with chronic heart failure

\begin{tabular}{|c|c|c|c|c|c|c|c|}
\hline & \multicolumn{4}{|c|}{ Time after infusion (min) } & \multicolumn{3}{|l|}{ Exercise } \\
\hline & 0 & 10 & 20 & 30 & Pre & Post & Difference \\
\hline \multicolumn{8}{|c|}{ Systolic blood pressure (mm Hg) } \\
\hline L-arginine & $121(4)$ & $116(4)$ & $122(4)$ & $125(5)$ & $123(4)$ & $164(7)^{\star \star}$ & \\
\hline Placebo & $122(5)$ & $123(4)$ & $123(5)$ & $125(5)$ & $131(6)$ & $163(6)^{\star \star}$ & NS \\
\hline \multicolumn{8}{|c|}{ Diastolic blood pressure $(\mathrm{mm} \mathrm{Hg})$} \\
\hline L-arginine & $75(3)$ & $67(3)$ & $71(4)$ & $72(3)$ & $71(3)$ & $90(4)^{\star \star}$ & \\
\hline Placebo & $72(3)$ & $72(2)$ & $71(2)$ & $74(3)$ & $72(3)$ & $91(6)^{\star \star}$ & NS \\
\hline \multicolumn{8}{|c|}{ Heart rate (beats/min) } \\
\hline L-arginine & $66(4)$ & $64(3)$ & $66(3)$ & $69(3)$ & $82(4)$ & $135(7)^{\star \star}$ & \\
\hline Placebo & $65(4)$ & $63(4)$ & $63(4)$ & $65(3)$ & $78(4)$ & $129(7)^{\star \star}$ & NS \\
\hline
\end{tabular}

Values are mean (SEM).

$\star \star p<0.01 v$ pre-exercise. 

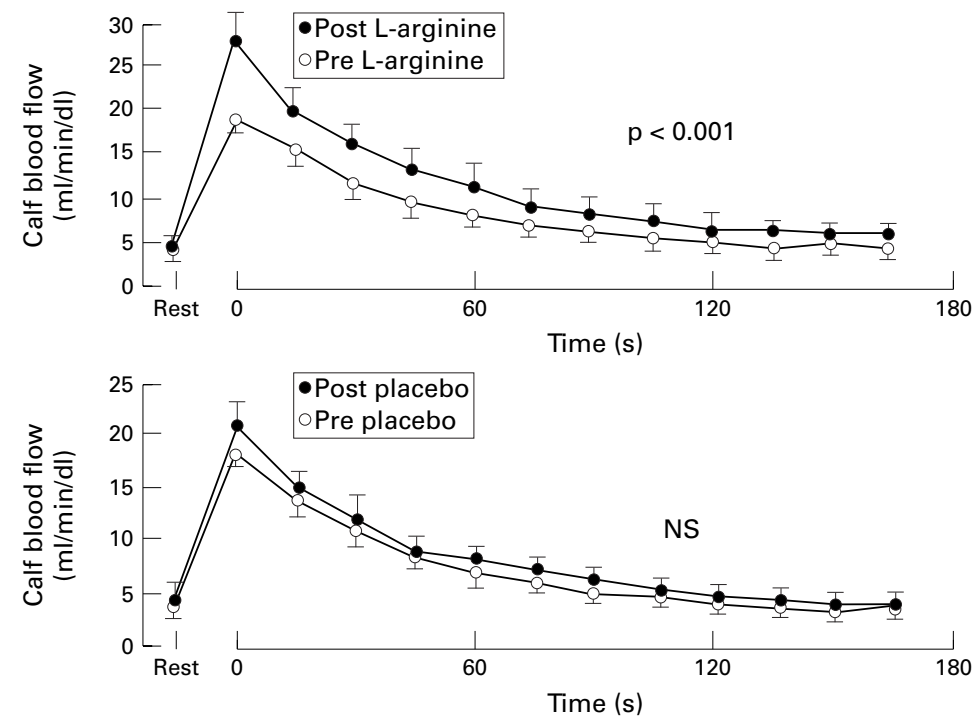

Figure 2 Calf blood flow response after abrupt release of five minute thigh occlusion before (O) and after (-) infusion of L-arginine (upper panel) and placebo (lower panel) in patients with chronic heart failure. Error bars $=S E M$.

infusion while the subject remained supine. Within 15 minutes of completion of the blood flow measurement, a symptom limited cardiopulmonary exercise test was performed using a bicycle ergometer. Within a two minute period after cessation of the cardiopulmonary exercise test, postexercise calf blood flow response (exercise induced reactive hyperaemia) was measured.

CARDIOPULMONARY EXERCISE TEST

The cardiopulmonary exercise test was carried out with the subject in an upright position on an electronically braked bicycle ergometer, as previously reported. ${ }^{10}$ In brief, patients warmed up at rest for three minutes on the ergometer, and then entered the work phase, starting at a rate of $10 \mathrm{~W}$ for three minutes. This was increased to $1 \mathrm{~W}$ per 4 seconds at 50 rpm. During the test, expired gas was monitored continuously on a breath by breath basis using a respiromonitor system (AE 280, Minato, Osaka, Japan). The gas analysers measured oxygen uptake, carbon dioxide

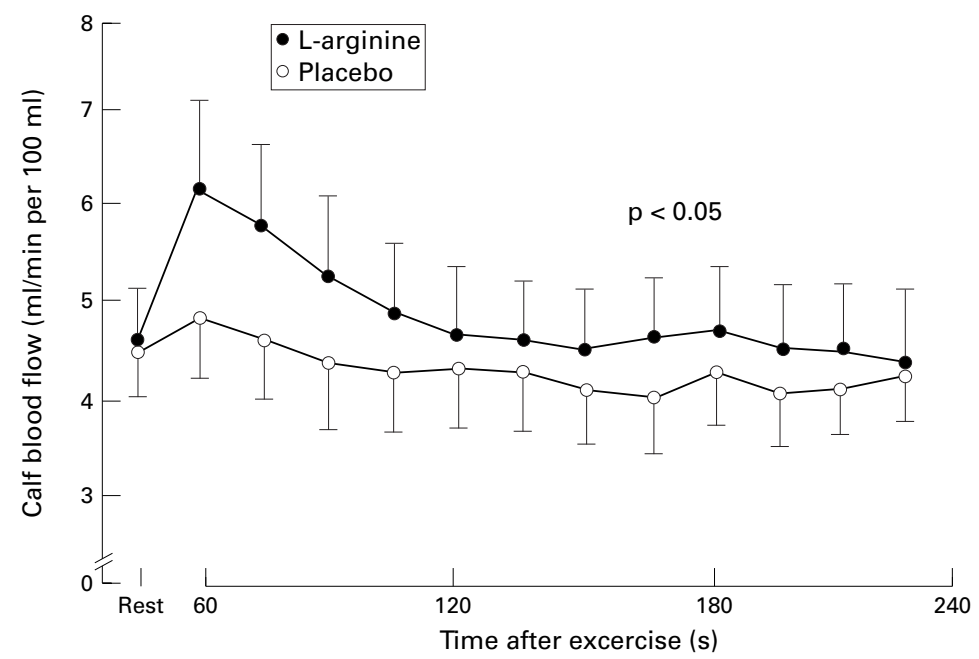

Figure 3 Calf blood flow response after ergometric exercise after L-arginine ( $\bullet$ ) and placebo (O) infusion in patients with chronic heart failure. Error bars = SEM. production, ventilation volume, and respiratory exchange ratio. These data were stored in an on-line computer, and peak oxygen uptake and anaerobic threshold (V-slope method) were determined. All patients discontinued the test owing to leg fatigue and shortness of breath. Systemic blood pressure and pulse rate of the left arm were measured by an automatic blood pressure monitoring system before and just after exercise, with the subject in a seated position.

BIOCHEMICAL VARIABLES

An 18 gauge cannula was inserted into a left forearm cutaneous vein for blood sampling. Blood samples were taken before and after experimental infusion, and immediately after the exercise test with the subject in a supine position. These samples were used for measurement of plasma levels of L-arginine, L-citrulline, catecholamines, and insulin.

STATISTICAL ANALYSIS

All values are presented as mean (SEM). Differences in calf blood flow, blood pressure, pulse rate, biochemical data, and exercise indices between the two experimental conditions (L-arginine $v$ placebo) were tested using paired $t$ tests or two way analysis of variance for repeated measurements. All calculated $p$ values were two tailed, and a value of $<0.05$ was considered significant.

\section{Results}

SYSTEMIC HAEMODYNAMIC VARIABLES

The effects of L-arginine infusion on resting and exercise induced systemic blood pressure and pulse rate are shown in table 1. Although systolic and diastolic blood pressure tended to decrease 10 minutes after L-arginine infusion, no significant differences in systemic blood pressure and pulse rate were observed between the L-arginine and placebo infusions. Changes in systemic haemodynamic variables during exercise were also similar for the two postinfusion phases.

\section{REACTIVE HYPERAEMIA}

Figure 2 shows the time course of calf blood flow after release of a five minute femoral artery occlusion before and after infusion of L-arginine (upper panel) or placebo (lower panel). L-arginine infusion had no effect on resting calf blood flow (4.4 (0.5) v 4.6 (0.4) $\mathrm{ml} / \mathrm{min} / \mathrm{dl}$ calf tissue; NS), but caused a rise in femoral artery occlusion induced reactive hyperaemia compared with the preinfusion state (peak flow, 28.9 (3.1) v 19.6 (1.5) $\mathrm{ml} / \mathrm{min} / \mathrm{dl}$ calf tissue; $\mathrm{p}<0.001)$. The peak value after L-arginine infusion was comparable with the value obtained in the healthy control subjects (32.6 (2.5) $\mathrm{ml} / \mathrm{min} / \mathrm{dl}$ calf tissue; NS). Placebo infusion had no significant effect on resting calf blood flow (4.1 (0.4) $v 4.5(0.4)$ $\mathrm{ml} / \mathrm{min} / \mathrm{dl}$ of calf tissue; NS) or femoral artery occlusion induced reactive hyperaemia (peak flow, 20.9 (1.8) v 19.1 (1.4) $\mathrm{ml} / \mathrm{min} / \mathrm{dl}$ calf tissue; NS). When reactive hyperaemic responses were compared in a time controlled manner (pre-L-arginine $v$ pre-placebo; post-L-arginine 

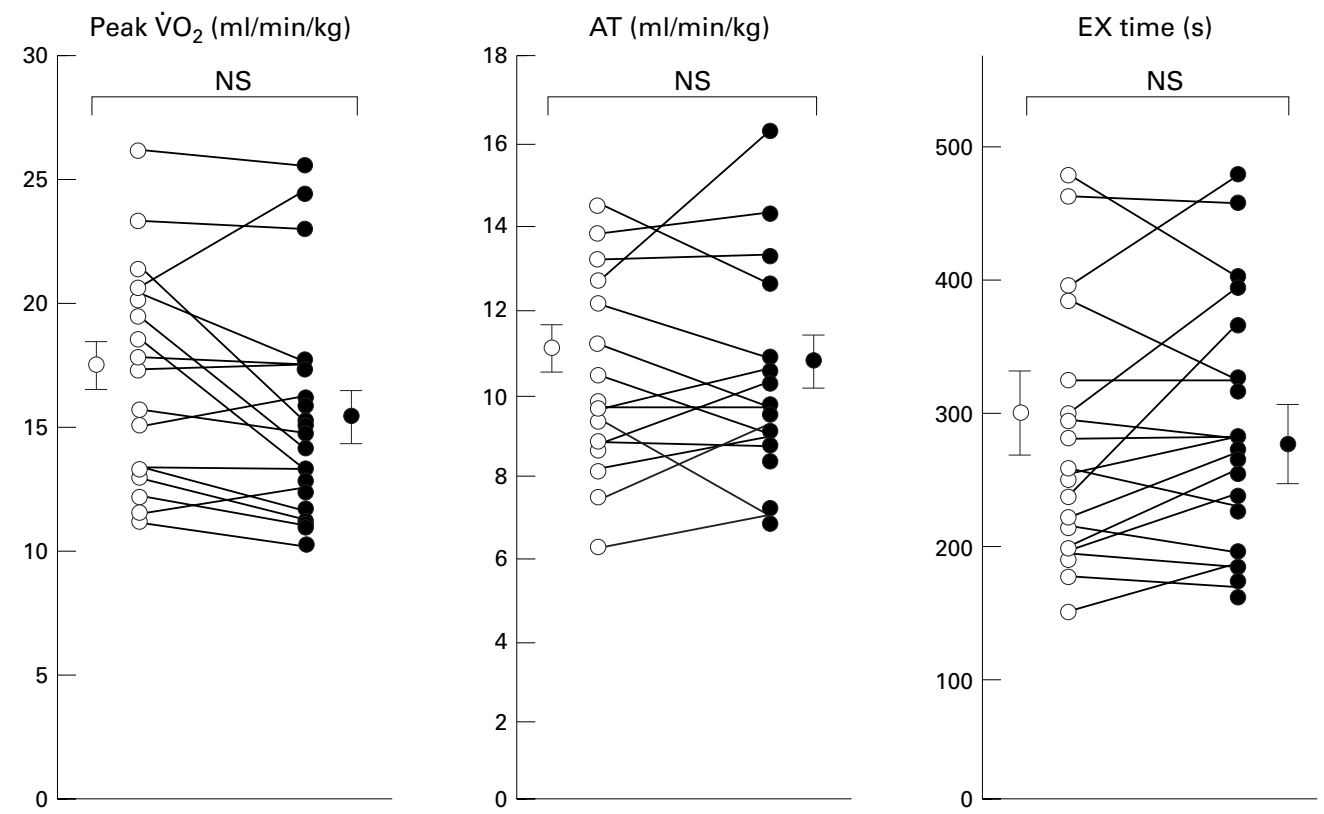

Figure 4 Changes in peak oxygen uptake (peak $\dot{V}_{\mathrm{O}_{2}}$ ) (left), anaerobic threshold (AT) (centre), and exercise (EX) time (right) measured after infusion of L-arginine (O) and placebo $(\bullet)$ in patients with chronic heart failure.

$v$ post-placebo), preinfusion reactive hyperaemia did not differ significantly between the two experimental infusions (peak flow, 19.6 (1.5) v $19.1(1.4) \mathrm{ml} / \mathrm{min} / \mathrm{dl}$ calf tissue; NS). Reactive hyperaemia after L-arginine infusion was augmented compared with placebo (peak flow, $28.9(3.1) v 20.9(1.8) \mathrm{ml} / \mathrm{min} / \mathrm{dl}$ of calf tissue; $\mathrm{p}<0.001)$.

Calf blood flow response following ergometric exercise (exercise induced reactive hyperaemia) is shown in fig 3. After L-arginine infusion, exercise induced calf blood flow change was enhanced compared with placebo (peak flow, $4.8(0.4)$ v $6.0(0.8) \mathrm{ml} / \mathrm{min} / \mathrm{dl}$ calf tissue; $\mathrm{p}<0.05)$.

EXERCISE INDICES

Changes in the indices measured by the cardiopulmonary exercise test are shown in fig 4. There was no significant difference between the two experimental conditions in exercise capacity, as defined by peak oxygen uptake

Table 2 Effect of $L$-arginine and placebo infusions on plasma concentrations of L-arginine, L-citrulline, noradrenaline, adrenaline, dopamine, and insulin in patients with chronic heart failure

\begin{tabular}{|c|c|c|c|c|}
\hline & Baseline & After infusion & After exercise & Differences \\
\hline \multicolumn{5}{|c|}{ Plasma L-arginine (pg/ml) } \\
\hline L-arginine & $25(7)$ & $1306(95)^{\star \star}$ & $464(30)^{\star \star}$ & \\
\hline Placebo & - & - & - & - \\
\hline \multicolumn{5}{|c|}{ Plasma L-citrulline (pg/ml) } \\
\hline L-arginine & $8.2(0.4)$ & $10.1(0.5)^{\star \star}$ & $11.6(0.6)^{\star \star}$ & \\
\hline Placebo & - & - & - & - \\
\hline \multicolumn{5}{|c|}{ Plasma noradrenaline $(\mathrm{pg} / \mathrm{ml})$} \\
\hline L-arginine & $307(47)$ & $320(53)$ & $1359(238)^{\star \star}$ & \\
\hline Placebo & $297(32)$ & $268(33)$ & $1293(287)^{\star \star}$ & NS \\
\hline \multicolumn{5}{|c|}{ Plasma adrenaline $(\mathrm{pg} / \mathrm{ml})$} \\
\hline L-arginine & $40(11)$ & $41(10)$ & $144(23)^{\star}$ & \\
\hline Placebo & $44(10)$ & $39(12)$ & $144(47)^{\star}$ & NS \\
\hline \multicolumn{5}{|c|}{ Plasma dopamine $(\mathrm{pg} / \mathrm{ml})$} \\
\hline L-arginine & $33(12)$ & $29(11)$ & $36(8)$ & \\
\hline $\begin{array}{l}\text { Placebo } \\
\text { Pa }\end{array}$ & $29(12)$ & $26(11)$ & $44(15)$ & NS \\
\hline \multicolumn{5}{|c|}{ Plasma insulin (IU/ml) } \\
\hline L-arginine & $20(4)$ & $67(15)^{\star}$ & $16(5)$ & \\
\hline Placebo & $27(6)$ & $46(12)^{\star}$ & $21(6)$ & $\mathrm{p}<0.05$ \\
\hline
\end{tabular}

Values are mean (SEM)

${ }^{\star} \mathrm{p}<0.05 ;{ }^{\star \star} \mathrm{p}<0.01 v$ baseline. (placebo 17.1 (1.0) $v$ L-arginine 15.8 (1.1) $\mathrm{ml} / \mathrm{min} / \mathrm{kg}(\mathrm{NS})$ ), anaerobic threshold (placebo $10.5(0.6) v$ L-arginine $10.4(0.7) \mathrm{ml} / \mathrm{min} / \mathrm{kg}$ (NS)), and exercise time (placebo 296 (23) $v$ L-arginine, 283 (22) seconds (NS)).

\section{BIOCHEMICAL MARKERS}

Changes in plasma L-arginine and L-citrulline levels are shown in table 2. Compared with baseline values, plasma concentrations of both increased significantly after L-arginine infusion and remained high after exercise. Table 2 also shows changes in plasma catecholamines and insulin. Plasma noradrenaline and adrenaline increased significantly after exercise compared with baseline values, but did not differ between the L-arginine and placebo experiments. Plasma insulin rose above baseline after both infusions, while the rise after L-arginine infusion was significantly higher than after placebo infusion $(\mathrm{p}<0.05)$.

\section{Discussion}

Peripheral hypoperfusion limits blood flow to working skeletal muscle, and may reduce exercise capacity in patients with chronic heart failure. ${ }^{1-3}$ It has been suggested recently that limb vascular dysfunction in this disorder may be partly caused by impaired production or action of $\mathrm{NO}$ in the peripheral vasculature. ${ }^{4-6}$ Several studies have described the effect of L-arginine supplementation on local circulation in the upper limb in patients with chronic heart failure. ${ }^{16} 17$ In these studies it was reported that intra-arterial infusion of L-arginine augmented the acetylcholine induced vasodilator response and ischaemia induced reactive hyperaemia in the forearm in patients with chronic heart failure. It has also been reported that changes in forearm blood flow after handgrip exercise are enhanced by local infusion of L-arginine into the forearm. ${ }^{17}$ 
Furthermore, six weeks of oral L-arginine supplementation increased forearm blood flow during forearm exercise in patients with chronic heart failure. ${ }^{18}$ However, it remains unknown whether L-arginine supplementation restores lower limb vasodilator capacity, which is a more important determinant of exercise capacity than forearm vascular function, and if so, whether the improvement directly affects objective exercise indices such as peak oxygen uptake and anaerobic threshold. In this study of patients with chronic heart failure, we showed that reactive hyperaemia induced by femoral artery occlusion and the calf blood flow response to ergometric exercise (exercise induced reactive hyperaemia) both increased after L-arginine infusion, but with no observable improvement in exercise capacity.

We were unable to determine the mechanism underlying this increase in lower limb vasodilator response after supplementation with L-arginine from the present results. However, there are several possible mechanisms, as follows. First, the enhancing effect of L-arginine on endothelium dependent vasodilator response has been shown to disappear after infusion of enantiomer D-arginine. ${ }^{19}{ }^{20} \mathrm{It}$ has been found that metabolites of $\mathrm{NO}\left(\mathrm{NO}_{2}\right.$ and $\mathrm{NO}_{3}$ ) and the intracellular second messenger system of NO (cyclic guanosine monophosphate) increase in urine and plasma after an intravenous infusion of L-arginine. ${ }^{21-23}$ Furthermore, Meredith et al showed that L-NMMA, an inhibitor of nitric oxide synthase, caused a significant inhibition of reactive hyperaemia, including peak blood flow. ${ }^{12}$ These findings suggest that the ischaemia and exercise induced reactive hyperaemia found in our subjects after L-arginine infusion may reflect augmentation of NO biosynthesis in the lower limb vascular bed. Second, it is known that L-arginine promotes insulin secretion from pancreatic $\beta$ cells. ${ }^{24}$ Insulin has been reported to have a vasodilator effect mediated by an endothelium derived, NO dependent mechanism. ${ }^{25-27}$ In the current study, plasma insulin concentrations were increased to a greater extent by the L-arginine infusion than by the placebo, raising the possibility that the vasodilator response was improved not only by the direct effect of L-arginine but also by a secondary effect of insulin. Third, it has recently been reported that L-arginine has a scavenger action for superoxide anions. ${ }^{28}$ It is therefore conceivable that NO auto-oxidation decreased in response to L-arginine supplementation, allowing the biological effect of $\mathrm{NO}$ to be enhanced.

In our study, L-arginine restored limb occlusion induced and exercise induced reactive hyperaemia in patients with chronic heart failure. This improvement suggests that regional blood flow to skeletal muscle may increase during exercise, and thus a beneficial effect on exercise capacity is to be expected. This, however, was not the case. Because indices of exercise capacity such as oxygen uptake are determined by cardiac output and arteriovenous oxygen difference, oxygen uptake is considered to be decreased if cardiac output or oxygen extraction is reduced. In human myocardial tissue obtained from patients with left ventricular dysfunction, there is evidence that a potent NO synthase is induced by cytokine stimulation, ${ }^{29}{ }^{30}$ and NO biosynthesis may increase markedly. Presumably, the supply of L-arginine is still a rate limiting factor for the production of $\mathrm{NO}$ in failing myocardium. If such mechanisms are operating in patients participating in our study, increased myocardial NO production after L-arginine supplementation may inhibit the positive chronotropic and inotropic cardiac response to adrenergic stimulation during exercise and impair left ventricular contraction. ${ }^{31}$ Indices of exercise capacity would thus remain unchanged in these patients with chronic heart failure. On the other hand, inducible NO synthase has been reported to be increased in skeletal muscle in patients with chronic heart failure. ${ }^{32}$ If NO biosynthesis is increased in skeletal muscle after supplementation with L-arginine, muscle contraction may be inhibited and exercise capacity reduced.

Rector et al have reported that exercise capacity, as represented by a six minute walk test, improved in patients with chronic heart failure after six weeks of oral administration of L-arginine. ${ }^{18}$ However, it is not surprising that the acute administration of $\mathrm{L}$-arginine does not improve exercise capacity, as previous studies have shown that the administration of several drugs known to have beneficial haemodynamic effects does not result in an immediate improvement in exercise capacity. ${ }^{33}{ }^{34}$ Further studies examining the effects of L-arginine administration on limb vascular function, cardiac pump function, and exercise capacity will be necessary before any conclusions can be reached about the possible clinical value this agent in patients with chronic heart failure.

Intravenous infusion of L-arginine had no significant effect on blood pressure in our subjects with chronic heart failure, in contrast with several previous reports that have shown a reduction in systemic blood pressure in healthy young subjects given a similar dose of L-arginine. ${ }^{35} 36$ This difference may reflect the inclusion of several elderly patients with complicating atherosclerosis in our study, as a recent report has shown that the haemodynamic effects of L-arginine infusion are attenuated in elderly males with atherosclerotic risk factors. ${ }^{37}$

In conclusion, systemic supplementation with the NO precursor L-arginine increased lower limb reactive hyperaemia but failed to improve exercise capacity in patients with chronic heart failure.

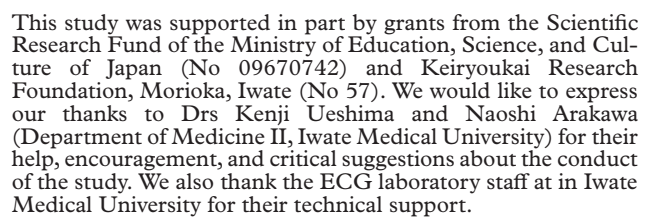

This study was supported in part by grants from the Scientific Research Fund of the Ministry of Education, Science, and CulFoundation, Morioka, Iwate (No 57). We would like to express our thanks to Drs Kenji Ueshima and Naoshi Arakawa help, encouragement, and critical suggestions about the conduct at in Iwate

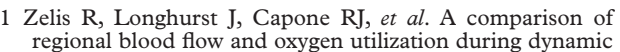
regional blood flow and oxygen utilization during dynamic forearm exercise in normal subjects and patients
gestive heart failure. Circulation 1974;50:137-43. 
2 Wilson JR, Martin JL, Schwartz D, et al. Exercise intolerance in patients with chronic heart failure: role of impaired nutritive flow to skeletal muscle Circulation 1984

3 LeJemtel TH, Maskin CS, Lucido D, et al. Failure to augment maximal limb blood flow in response to one-leg versus two-leg exercise in patients with severe heart failure. Circulation 1986;74:245-51.

4 Kubo SH, Rector TS, Bank AJ, et al. Endotheliumdependent vasodilation is attenuated in patients with heart failure. Circulation 1991;84:1589-96.

5 Drexler H, Hayoz D, Munzel T, et al. Endothelial function in chronic congestive heart failure. Am f Cardiol 1992;69: 1596-601

6 Katz SD, Biasucci L, Sabba C, et al. Impaired endotheliummediated vasodilation in the peripheral vasculature of patients with congestive heart failure. $\mathcal{F} \mathrm{Am}$ Coll Cardiol 1992;19:918-25.

7 Joannides R, Haefeli WE, Linder L, et al. Nitric oxide is responsible for flow-dependent dilatation of human periphresponsible for flow-dependent dilatation of human periph-

8 Lindsay DC, Holdright DR, Clarke D, et al. Endothelial control of lower limb blood flow in chronic heart failure. control of lower limb b

9 Jondeau G, Katz SD, Toussaint JF, et al. Regional specificity of peak hyperemic response in patients with congestive heart failure: correlation with peak aerobic capacity. f $\mathrm{Am}$ Coll Cardiol 1993;22:1399-402.

10 Chiba M, Nakamura M, Kanaya Y, et al. Improvement in lower limb vasodilatory reserve and exercise capacity in patients with chronic heart failure due to valvular heart disease. Eur Heart f 1997; 18:1931-6.

11 Tagawa T, Imaizumi T, Endo T, et al. Role of nitric oxide in reactive hyperemia in human forearm vessels. Circulation 1994; 90:2285-90.

12 Meredith IT, Currie KE, Anderson TJ, et al. Postischemic vasodilation in human forearm is dependent on endothelium-derived nitric oxide. Am f Physiol 1996;270 H1435-40.

13 Palmer RM, Ashton DS, Moncada S. Vascular endothelial cells synthesize nitric oxide from L-arginine. Nature 1988 cells synthesiz

14 Palmer RM, Rees DD, Ashton DS, et al. L-arginine is the physiological precursor for the formation of nitric oxide in endothelium-dependent relaxation. Biochem Biophys Res Commun 1988;153:1251-6.

15 Bode-Boger SM, Boger RH, Alfke H, et al. L-arginine induces nitric oxide-dependent vasodilation in patients with critical limb ischemia. A randomized, controlled study. Circulation 1996;93:85-90.

16 Hirooka $\mathrm{Y}$, Imaizumi $\mathrm{T}$, Tagawa $\mathrm{T}$, et al. Effects of L-arginine on impaired acetylcholine-induced and ischemic vasodilation of the forearm in patients with heart failure. Circulation 1994;90:658-68

17 Kubota T, Imaizumi T, Oyama J, et al. L-arginine increases exercise-induced vasodilation of the forearm in patients with heart failure. fpn Circ f 1997;61:471-80.

18 Rector TS, Bank AJ, Mullen KA, et al. Randomized, double-blind, placebo-controlled study of supplemental double-blind, placebo-controlled study of supplemental oral L-arginine in

19 Creager MA, Gallagher SJ, Girerd XJ, et al. L-arginine improves endothelium-dependent vasodilation in hypercholesterolemic humans. F Clin Invest 1992;90:1248-53.

20 Panza JA, Casino PR, Badar DM, et al. Effect of increased availability of endothelium-derived nitric oxide precursor on endothelium-dependent vascular relaxation in normal subiects and in patients with essential hypertension. Circulation 1993;87:1475-81.

21 Bode-Boger SM, Boger RH, Creutzig A, et al. L-arginine infusion decreases peripheral arterial resistance and inhibits platelet aggregation in healthy subjects. Clin Sci 1994;87:303-10.

22 Koifman B, Wollman Y, Bogomolny N, et al. Improvement of cardiac performance by intravenous infusion of $\mathrm{L}$-arginine in patients with moderate congestive heart failure. $\mathcal{F}$ Am Coll Cardiol 1995;26:1251-6.

23 Smulders RA, Aarsen M, Teerlink T, et al. Haemodynamic and biochemical responses to L-arginine and L-lysine infusions in normal subjects: L-arginine-induced vasodilatation cannot be explained by non-specific effects of cationic amino acids. Clin Sci 1997;92:367-74.

24 Henquin JC, Meissner HP. Effects of amino acids on membrane potential and $86 \mathrm{Rb}$ + fluxes in pancreatic beta-cells. Am F Physiol 1981;240:E245-52.

25 Steinberg HO, Brechtel G, Johnson A, et al. Insulinmediated skeletal muscle vasodilation is nitric oxide dependent. A novel action of insulin to increase nitric oxide release. 7 Clin Invest 1994;94:1172-9.

26 Baron AD. Hemodynamic actions of insulin. Am f Physiol 1994;267:E187-202.

27 Giugliano D, Marfella R, Verrazzo G, et al. The vascular effects of L-arginine in humans. The role of endogenous insulin. 7 Clin Invest 1997;99:433-8.

28 Wascher TC, Posch K, Wallner S, et al. Vascular effects of L-arginine: anything beyond a substrate for the $\mathrm{NO}$ synthase? Biochem Biophys Res Commun 1997;234:35-8.

29 Habib FM, Springall DR, Davies GJ, et al. Tumour necrosis factor and inducible nitric oxide synthase in dilated cardiomyopathy. Lancet 1996;347:1151-5.

30 Satoh M, Nakamura M, Tamura G, et al. Inducible nitric oxide synthase and tumor necrosis factor-alpha in myocardium in human dilated cardiomyopathy. $7 \mathrm{Am}$ Coll Cardiol 1997;29:716-24.

31 Hare JM, Loh E, Creager MA, et al. Nitric oxide inhibits the positive inotropic response to beta-adrenergic stimulation in humans with left ventricular dysfunction. Circulation 1995;92:2198-203.

32 Adams V, Yu J, Mobius-Winkler S, et al. Increased inducible nitric oxide synthase in skeletal muscle biopsies from patients with chronic heart failure. Biochem Mol Med 1997; 61:152-60.

33 Wilson JR, Martin JL, Ferraro N. Impaired skeletal muscle nutritive flow during exercise in patients with congestive heart failure: role of cardiac pump dysfunction as determined by the effect of dobutamine. Am $\mathcal{F}$ Cardiol 1984;53:1308-15.

34 Zelis R, Sinoway LI, Musch TI, et al. Regional blood flow in congestive heart failure: concept of compensatory mechanisms with short and long time constants. Am 7 Cardiol 1988;62:2-8E.

35 Laghi Pasini F, Frigerio C, Blardi P, et al. Evidence of an adenosine-dependent mechanism in the hypotensive effect of L-arginine in man. Clin Exp Pharmacol Physiol 1995;22: 254-9.

36 Higashi Y, Oshima T, Ono N, et al. Intravenous administration of L-arginine inhibits angiotensin-converting enzym in humans. $\mathcal{F}$ Clin Endocrinol Metab 1995;80:2198-202.

37 Giugliano D, Marfella R, Verrazzo G, et al. L-arginine for testing endothelium-dependent vascular functions in health and disease. Am f Physiol 1997;273:E606-12. 